University of Wollongong

Research Online

Faculty of Engineering and Information

Faculty of Engineering and Information

Sciences - Papers: Part A

Sciences

$1-1-2015$

Development of an MRE adaptive tuned vibration absorber with selfsensing capability

Shuaishuai Sun

University of Wollongong, ss886@uowmail.edu.au

Jian Yang

University of Wollongong, jy937@uowmail.edu.au

Weihua Li

University of Wollongong, weihuali@uow.edu.au

Huaxia Deng

Hefei University of Technology

Haiping Du

University of Wollongong, hdu@uow.edu.au

See next page for additional authors

Follow this and additional works at: https://ro.uow.edu.au/eispapers

Part of the Engineering Commons, and the Science and Technology Studies Commons

Research Online is the open access institutional repository for the University of Wollongong. For further information contact the UOW Library: research-pubs@uow.edu.au 


\title{
Development of an MRE adaptive tuned vibration absorber with self-sensing capability
}

\begin{abstract}
In this paper, self-sensing technology was introduced into an adaptive tuned vibration absorber, incorporating a laminated magnetorheological elastomer (MRE) structure, a hybrid magnetic system and a self-sensing component. The adoption of the laminated MRE structure and the hybrid magnetic system enables the absorber to have higher lateral flexibility and a wider effective frequency range. The integration of the self-sensing capability allows the absorber to operate without sensors and, at the same time, greatly reduces costs, required space and maintenance. A series of experiments were conducted to measure the frequency shift property, to verify the self-sensing capability and to evaluate its effectiveness on vibration reduction. The experimental results show that the natural frequency of the proposed absorber can be changed to $4.8 \mathrm{~Hz}$ at $-3 \mathrm{~A}$ and $11.3 \mathrm{~Hz}$ at $3 \mathrm{~A}$ from $8.5 \mathrm{~Hz}$ at $0 \mathrm{~A}$, the frequency of the selfsensed voltage equals the excitation frequency and, more importantly, the vibration control effectiveness of the self-sensing MRE absorber is experimentally verified and it is more effective on vibration reduction than a passive absorber.
\end{abstract}

\section{Keywords}

vibration, development, absorber, mre, self, sensing, adaptive, capability, tuned

\section{Disciplines}

Engineering | Science and Technology Studies

\section{Publication Details}

Sun, S., Yang, J., Li, W., Deng, H., Du, H. \& Alici, G. (2015). Development of an MRE adaptive tuned vibration absorber with self-sensing capability. Smart Materials and Structures, 24 (9), 095012-1-095012-10.

\section{Authors}

Shuaishuai Sun, Jian Yang, Weihua Li, Huaxia Deng, Haiping Du, and Gursel Alici 


\title{
Development of a MRE Adaptive Tuned Vibration Absorber with Self-sensing capability
}

\author{
Shuaishuai $\operatorname{Sun}^{1}$, Jian Yang ${ }^{1}$, Weihua $\mathrm{Li}^{* 1}$, Huaxia Deng ${ }^{* 2}$, Haiping $\mathrm{Du}^{3}$, and Gursel Alici ${ }^{1}$ \\ ${ }^{1}$ School of Mechanical, Materials and Mechatronic Engineering, University of Wollongong, Wollongong, \\ NSW 2522, Australia \\ ${ }^{2}$ School of Instrument Science and Optoelectronics Engineering, Hefei University of Technology, Hefei, Anhui, \\ 230027, China \\ ${ }^{3}$ School of Electrical, Computer \& Telecommunications Engineering, University of Wollongong, Wollongong, \\ NSW 2522, Australia \\ Corresponding Authors: weihuali@uow.edu.au and hxdeng@hfut.edu.cn
}

\begin{abstract}
In this paper, the self-sensing technology was introduced to an adaptive tuned vibration absorber which incorporates the laminated MRE structure, the hybrid magnetic system, and the self-sensing component. The adoption of the laminated MRE structure and the hybrid magnetic system enables the absorber to have a higher lateral flexibility and wider effective frequency range. The integration of the self-sensing capability makes the absorber leave out the usage of sensors and at the same time is a big relief on the cost, space, and maintenance. A series of experiments were conducted to measure the frequency-shift property, to verify the self-sensing capability, and to evaluate its effectiveness on vibration reduction. The experimental results shows that the natural frequency of the proposed absorber can be changed to $4.8 \mathrm{~Hz}$ at $-3 \mathrm{~A}$ and $11.3 \mathrm{~Hz}$ at $3 \mathrm{~A}$ from $8.5 \mathrm{~Hz}$ at $0 \mathrm{~A}$, that the frequency of the selfsensed voltage equals the excitation frequency, and that, more importantly, the vibration control effectiveness of the self-sensing MRE absorber is experimentally verified and it is more effective on vibration reduction than the passive absorber.
\end{abstract}

Key words: Magnetorheological elastomer, ATVA, Self-sensing, Vibration reduction. 


\section{Introduction}

To circumvent the vibration caused shortcomings of ride discomfort, noise, accuracy reduction and mechanical failure, tuned vibration absorber has been widely applied to control unwanted vibrations induced by the engines, high speed machines, the precision Machinery and so on. To date, passive [1], active [2], and adaptive [3, 4] tuned vibration absorber have been proposed. Regarding the passive TVAs, its working frequency range is limited to around the natural frequency of the TVA although it has the advantageous of structure simplicity and cost effectiveness. The active TVAs possess the best vibration absorption performance. Its high energy consuming and poor stability, however, makes active TVA difficult to find practical usage. The adaptive tuned vibration absorbers (ATVAs) are the one of the best options to broaden the working frequency ranges of TVA while maintain low energy consuming and stability.

Many approaches have been proposed to develop ATVAs, among which MRE based ATVA outperformed because of its quick and reversible stiffness variability, stability and cost effectiveness. MRE, as a smart stiffness controllable material, has been widely applied to vibration control [5-9], especially for ATVA. Inspired by Ginder's pioneering work [10], Deng et al. reported a series of MRE absorbers working in shear working mode for vertical vibration control $[11,12]$, which extended the frequency range of the absorber from 55 to 82 Hz. Hoang et al presented an ATVA based on MREs to reduce vibrations in vehicle powertrain systems [13]. Zhang and Li developed a new control algorithm to attenuate vibration with multi frequencies [14]. Sun et al. investigated the difference of frequency shift range of MRE absorber working in shear and squeeze mode and further developed a new compact MRE absorber that works in a squeeze mode $[6,15]$ to widen the frequency range and extend the scope of its application; they also experimentally verified how effectively it attenuated the vibrations. To overcome the damping effect and increase the absorber's effectiveness, Gong's group used a voice motor to counteract the effect of damping [16, 17]. The main working principle of the MRE based absorber for vibration protection is to absorb the vibration energy by making the natural frequency of the absorber matched with the excitation frequency through the adjustment of the MRE stiffness. The key point, therefore, is to collect the real-time frequency data of the excitation signals and pass it to the absorber as the reference of the stiffness adjustment. Traditionally speaking, sensors must be supplied for the MRE absorber to acquire the relevant time-domain signals and controllers are always 
needed to transfer the acquired signals into the frequency-domain information. The working flow of ATVAs can be detailed and described by Fig.1. A sensor mounted on the object is used to measure the vibration information. The vibration signal is then transferred to the controller. The controller will calculate and generate a control signal to control the ATVA via an power amplifier. Obviously, the sensors are essential to the system to acquire necessary information, which, however, also adds burden to the cost, space limitation, and the complexity of system. So the approach to leave out the sensors in the ATVA system to lower the cost, space, maintenance and to easy the structure is important to study. Undoubtedly, the self-sensing technology is a good choice because it will integrate the function of sensing into the absorber itself.

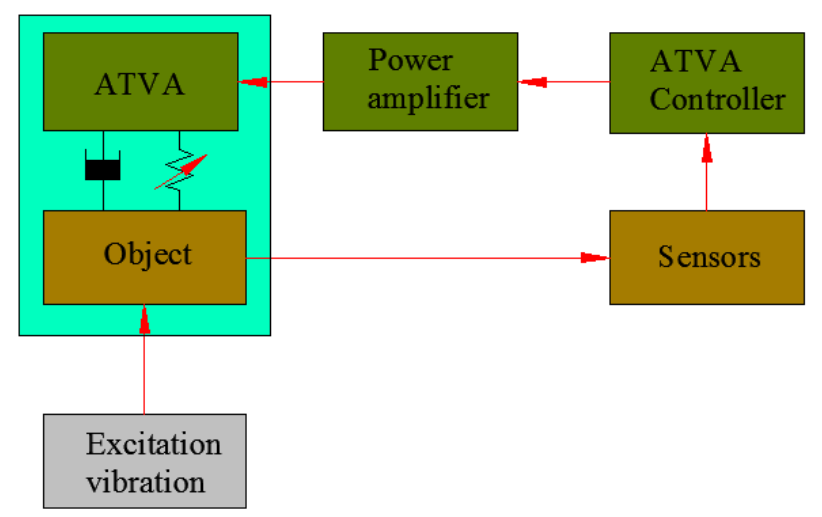

Fig.1. The system of the traditional ATVA

The concept of self-sensing refers to the capability of one mechanical system to measure and deliver dynamic information in real time using the self-contained component of the system without the requirement for extra sensors [18-20]. For instance, the self-sensing technology for the self-induced velocity, displacement, and forces has been developed and feasible in the magnetorheological (MR) damper [21-26]. The practical implementation of the self-sensing feature embellishing the MRE absorber, however, has been rarely investigated according to the best knowledge of the authors. Based on this motivation, this paper innovatively developed an MRE based ATVA with the capability of self-sensing. The components of the proposed ATVA mainly include the multilayered MRE structure, the hybrid magnetic system which consists of excitation coil and permanent magnets, self-sensing coil, the biggest highlight in this work, to self-sense the excitation frequency, and the steel yoke which serves the effective mass of the oscillator. The realisation of the self-sensing capability is based on the Faraday's Law of Induction that an electromotive force across a conductor is produced when the conductor is exposed to a varying magnetic field. The integration of the self-sensing 
capability makes MRE absorber efficient in cost, compact in structure, and versatile in function. In addition, self-sensing MRE absorber possesses another advantage compared with conventional self-sensing devices, which is low requirement of signal accuracy. The reason is detailed as follows. MRE absorber only needs to acquire the dominant frequency of the excitation to track with, which means frequency domain information of the excitation vibration will satisfy the need of MRE absorber. As the power spectral density of noise in self-sensing signal is much lower than the actual vibration signals, the signal noise will not affect the value of the dominant frequency. This advantage can reduce the accurate requirement of the original self-sensing signal and make it much easier and more cost effective to realise practical usage compared with self-sensing technology of MR damper or other devices.

This work is organized as follows: section 2 shows the structure, working principle, magnetic field density analysis, frequency shift analysis and prototype of the MRE absorber; Section 3 investigated the frequency-shift property of MRE absorber experimentally, Section 4 outlines the testing of its self-sensing capability; Section 5 is an verification of the vibration suppression performance of the self-sensing MRE absorber on a SDOF system; and Section 6 contains the conclusion.

\section{Development of the self-sensing MRE ATVA}

\subsection{The structure and working principle of the ATVA}

Following our prior works $[7,27]$ on multilayered MRE absorber and isolator, the selfsensing capability was further integrated to the laminate structured MRE absorber. The structure of the self-sensing is shown in Fig.2. The MRE based absorber mainly consists of the laminated steel-MRE structure, the hybrid magnetic system, a set of self-sensing coil, and a steel yoke. The laminated steel-MRE structure consists of 10 layers of $1 \mathrm{~mm}$ thick MRE sheets and 10 layers of $1 \mathrm{~mm}$ thickness steel sheets bonded in a sandwich pattern. The selfsensing MRE absorber inherited the advantages of the multilayered MRE structure which are strong vertical support capability, high lateral flexibility. In addition, the hybrid magnetic system enables the superimposed hybrid magnetic field can increase or decrease its strength, which leads to the increase or decrease of the lateral stiffness of the MRE structure. This property undoubtedly expands the frequency shift range of the absorber. In order to integrate the sensing component to the MRE absorber itself, this paper innovatively designed a self- 
inducing coil for the MRE absorber. The self-sensing coil centred with the MRE structure is mounted on the bottom plate leaving a 5mm gap with the steel yoke, as shown in Fig.2. The ingenious designed self-inducing coil avoided the extra requirement of spaces and magnetic systems by inserting the self-inducing coil to the gap and using the existing magnetic field, respectively. When the oscillator starts vibration laterally, the magnetic flux enclosed by the hundreds of turns of coil will be changing. According to Faraday's Law of Induction, an electromotive force will be generated.

\subsection{Analysis of the magnetic field density and frequency shift}

The hybrid magnetic system and frequency shift are critical important for self-sensing and vibration absorption performance. In this subsection, the hybrid magnetic field and frequency shift of the self-sensing absorber are carefully calculated and analysed. Fig. 2 and Table 1 illustrate the detailed size of the MRE absorber. As the first step, the magnetic resistances of each segment are calculated by the following equations.

The magnetic resistance of the ten MRE layers and ten steel layers can be calculated by:

$$
R_{1}=\frac{10 h_{2}}{\pi\left(d_{1} / 2\right)^{2} \mu_{1} \mu_{0}}+\frac{10 h_{2}}{\pi\left(d_{1} / 2\right)^{2} \mu_{2} \mu_{0}}
$$

The magnetic resistance of the two permanent magnets is:

$$
R_{2}=\frac{2 h_{3}}{\pi\left(d_{1} / 2\right)^{2} \mu_{3} \mu_{0}}
$$

The magnetic resistance of the two steel pillars is:

$$
R_{3}=\frac{2 h_{1}}{\pi\left(d_{1} / 2\right)^{2} \mu_{2} \mu_{0}}
$$

As the magnetic resistances of the gap and self-sensing coil are the same, their magnetic resistances can be calculated by:

$$
R_{4}=\frac{L_{3}+L_{4}}{\pi\left[\left(d_{3} / 2\right)^{2}-\left(d_{2} / 2\right)^{2}\right] \mu_{0} \mu_{4}}
$$

The magnetic resistance of the cylinder is given by:

$$
R_{5}=\frac{L_{2}+L_{1} / 2}{\pi\left[\left(d_{3} / 2\right)^{2}-\left(d_{2} / 2\right)^{2}\right] \mu_{2} \mu_{0}}
$$


The magnetic resistance of the top and bottom plates are

$$
R_{6}=\frac{2\left(\frac{d_{3}}{2}-\frac{d_{1}}{4}\right)}{\pi\left(d_{3} / 2\right) L_{1} \mu_{2} \mu_{0}}
$$

where $\mu_{0}$ is the vacuum permeability; $\mu_{1}$ is the relative permeability of the MRE; $\mu_{2}$ is the relative permeability of the $10 \#$ steel; $\mu_{3}$ is the relative permeability of the permanent magnet; $\mu_{4}$ is the relative permeability of the air and self-sensing coil.

The overall magnetic resistances is given by

$$
R_{m}=R_{1}+R_{2}+R_{3}+R_{4}+R_{5}+R_{6}
$$

Thus the following equation can be obtained based on Ohm's law:

$$
2 \mathrm{M} \pm \mathrm{NI}=B_{g} S_{g} R_{m}
$$

Where $\mathrm{M}$ is the magnetomotive force of permanent magnet and NI is the magnetomotive force of coil, $B_{g}$ is the magnetic flux density of resistance gap and $S_{g}$ is the flux area of resistance gap.

With the calculated magnetic field, the frequency shift of the MRE absorber can be obtained according to [27]

$$
f=\left\{\begin{array}{cc}
\frac{1}{2 \pi} \sqrt{\frac{\left(G_{o}+36 \phi \mu_{o} \mu_{l} \beta^{2}\left(B_{g} / \mu_{M R E} \mu_{o}\right)^{2}\left(\frac{a}{d}\right)^{3} \zeta\right) \mathrm{A}}{10 m h}} & \text { (If the iron particals do not saturate) } \\
\frac{1}{2 \pi} \sqrt{\frac{\left(G_{o}+4 \phi \mu_{o} \mu_{l} M_{S}^{2}\left(\frac{a}{d}\right)^{3}\right) \mathrm{A}}{10 m h}} & \text { (If the iron particals saturate) }
\end{array}\right.
$$

where $G_{o}$ is the initial shear modulus of MRE, $\phi$ is the volume fraction, $\beta=\left(\mu_{p}-\mu_{l}\right)\left(\mu_{p}+\right.$ $\left.2 \mu_{l}\right) \approx 1, \mu_{\mathrm{p}} \approx 1000$ and $\mu_{l} \approx 1$ are the relative permeability of the particles and silicon rubber, respectively. $\mu_{M R E}$ is the relative permeability of MRE, $a$ is the average particle radius, $d$ is the particle distance before deflection, $\zeta=\sum_{j=1}^{n} \frac{1}{j^{3}} \approx 1.202$. $A$ and $h$ are the effective area and thickness of the MRE sheet. $M_{S}$ is the saturation intensity of the particles. The theoretical analysis result of the frequency shift of the MRE absorber is shown in Fig.5. 

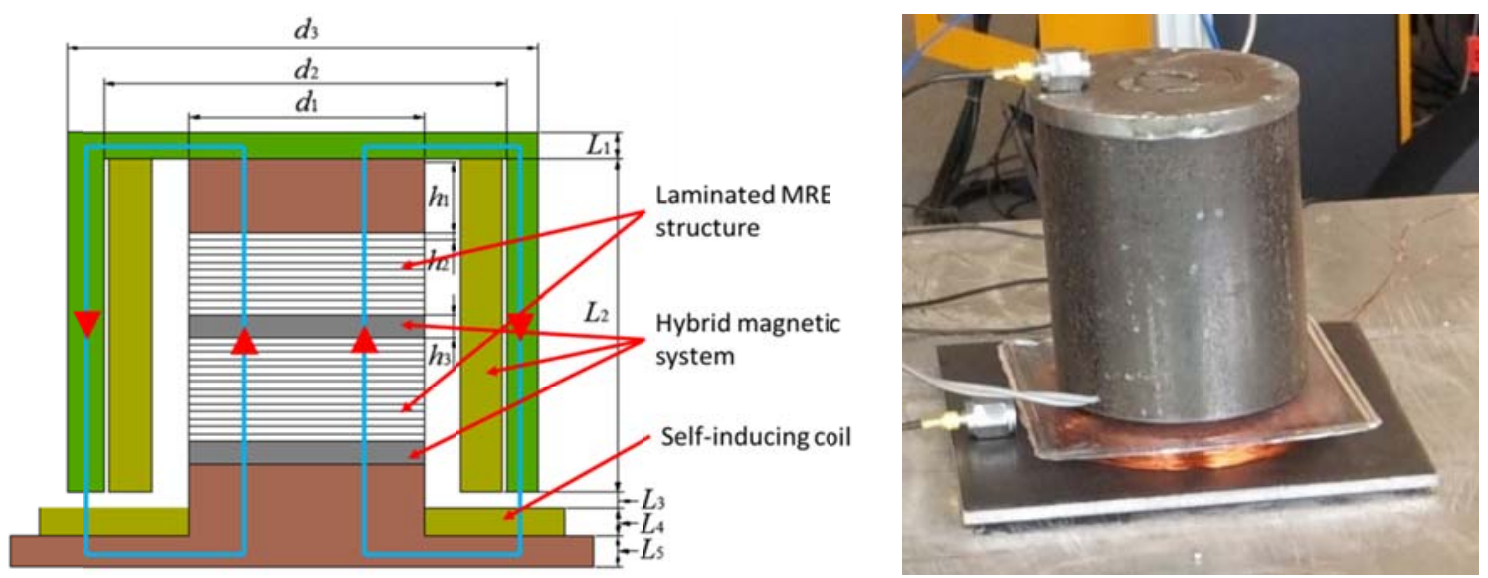

Fig.2. The detailed size and prototype of self-sensing MRE absorber

Table.1. Parameters of self-sensing MRE absorber

\begin{tabular}{|c|c|c|c|c|}
\hline Parameters & Values & & Parameters & Values \\
\cline { 1 - 2 } $\mathrm{h}_{1}$ & $40 \mathrm{~mm}$ & $\mathrm{~L}_{1}$ & $5 \mathrm{~mm}$ \\
\hline $\mathrm{h}_{2}$ & $1 \mathrm{~mm}$ & $\mathrm{~L}_{2}$ & $100 \mathrm{~mm}$ \\
\hline $\mathrm{h}_{3}$ & $5 \mathrm{~mm}$ & $\mathrm{~L}_{3}$ & $5 \mathrm{~mm}$ \\
\hline $\mathrm{d}_{1}$ & $35 \mathrm{~mm}$ & $\mathrm{~L}_{4}$ & $5 \mathrm{~mm}$ \\
\hline $\mathrm{d}_{2}$ & $80 \mathrm{~mm}$ & $\mathrm{~L}_{5}$ & $5 \mathrm{~mm}$ \\
\hline $\mathrm{d}_{3}$ & $90 \mathrm{~mm}$ & & Self-sensing coil & $400 \mathrm{turns}$ \\
\hline Excitation coil & $1000 \mathrm{turns}$ & & \\
\cline { 1 - 2 } & & & \\
\hline
\end{tabular}

\section{Experimental investigation of the frequency-shift property}

\subsection{Experimental setup for the frequency shift test of the proposed MRE absorber}

The investigation of the frequency-shift property is the fundamental yet necessary verification for being as an absorber. In this experiment, a series of tests using swept sinusoidal signals were conducted to measure the frequency-shift performance. Fig.3 illustrates the detailed experimental setup, which mainly consists of the shaker and the horizontal vibration platform. The horizontal vibration platform was fabricated by using a rectangular steel basement with two linear bearings mounted on it. An aluminum sheet was screwed onto the two linear bearings with the bottom plate of the laminated MRE absorber fixed on it. This vibration platform was forced to vibrate horizontally by a shaker (VTS, .VC 100-8) driven by a harmonic signal generated by a computer and amplified by a power amplifier (YE5871). A DC power supply (THURLBY-THANDAR, INSTRUMENTS LTD) was used to provide current signal to the absorber solenoid. In this test, two accelerometers (CA-YD-106) were installed onto the top and bottom plates of the MRE absorber, 
respectively, to measure their lateral acceleration. These accelerations were then transferred to the computer via the Data Acquisition (DAQ) board, while the signal collection, recording, and processing systems were developed using the LabVIEW program. With this system the transmissibility of the laminated MRE absorber was recorded and displayed directly onto the computer.

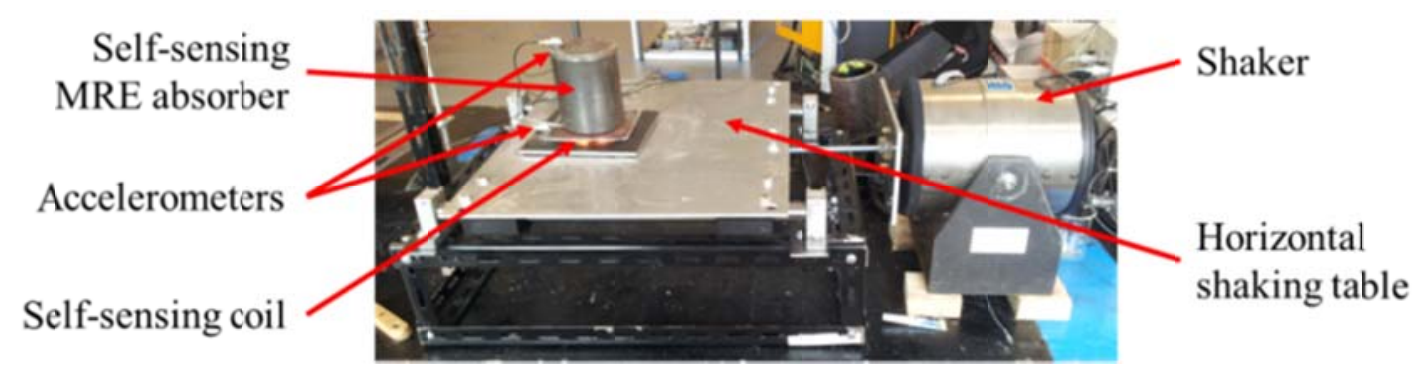

Fig.3. The frequency shift property test system

\subsection{Testing results}

In this test, the laminated MRE absorber was energized by a current signal varying from $-3 \mathrm{~A}$ to $3 \mathrm{~A}$ with a step of $1 \mathrm{~A}$ and the frequency range swept from $2 \mathrm{~Hz}$ to $15 \mathrm{~Hz}$. A total of 7 testing cases, therefore, were conducted. When the applied current was negative, the electromagnetic field was opposed to the initial magnetic field generated by the permanent magnets; otherwise, the two magnetic fields were in the same direction. Fig. 4 records the frequency-shift performances under various current conditions and Fig.5 presents the relationship between the currents and the natural frequencies. Fig. 5 shows that when the current changed from $0 \mathrm{~A}$ to $(-3) \mathrm{A}$, the natural frequency decreased from $8.5 \mathrm{~Hz}$ to $4.8 \mathrm{~Hz}$, while the natural frequency increased from $8.5 \mathrm{~Hz}$ to $11.3 \mathrm{~Hz}$ when the current was changed from $0 \mathrm{~A}$ to $3 \mathrm{~A}$. This test proved that the hybrid magnetic system has successfully realized the bi-directional control of the natural frequency of the absorber, which obviously widens the effective frequency range. In addition, the good fitness between the theoretical results and experimental results verified the correctness of the theoretical analysis in subsection 2.2. 


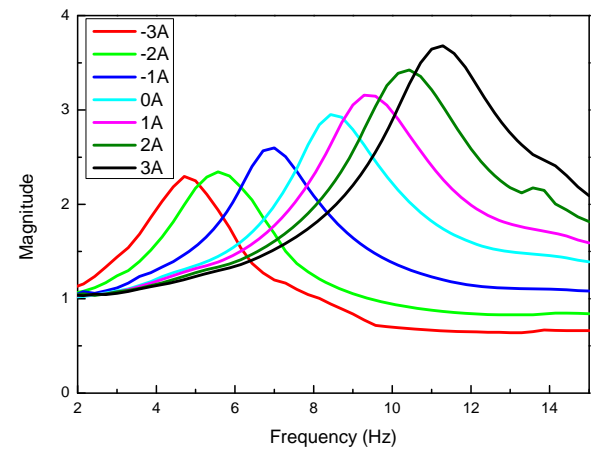

(a) Magnitude

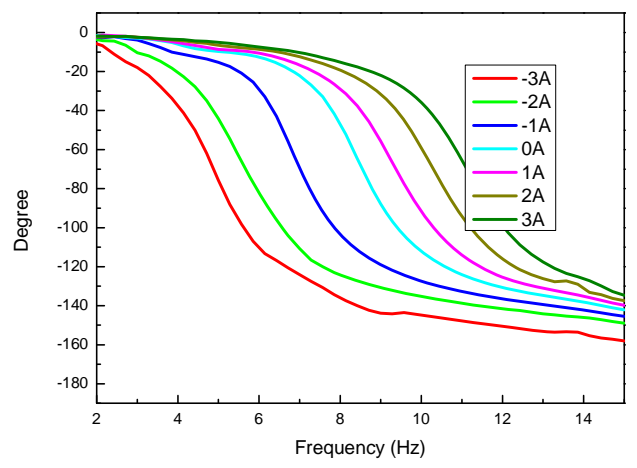

(b) Phase

Fig.4. The frequency shift property of the self-sensing MRE absorber

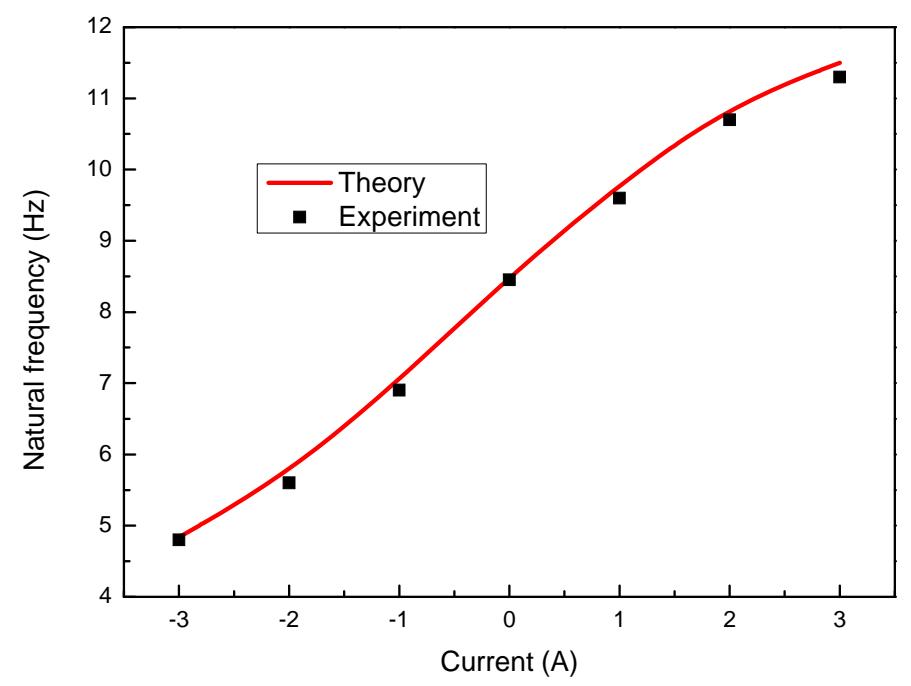

Fig.5. The relationship between the currents and natural frequencies

\section{Self-Sensing capability}

In this section, the self-sensing capability is investigated. The test system is similar to the one shown in Fig. 3 with only one difference that the self-sensed voltage signals were measured and passed to the computer through the DAQ board. Sinusoidal signals with different constant frequencies were chosen in this test. A total of 12 cases were tested with the constant frequency changed from $4 \mathrm{~Hz}$ to $15 \mathrm{~Hz}$ with a step of $1 \mathrm{~Hz}$. All the self-induced voltage signals were given in Fig.6. Generally speaking, the signal generated by the self-sensing coil is harmonic, as shown in Fig. 6. An exciting finding is the frequencies of the self-sensed 
voltage are the same as those excitation frequencies. The induced voltage of the coil can be calculated by the following equation:

$$
\mathrm{E}=\frac{\Delta \varphi}{\Delta t}=\dot{\Delta \varphi}
$$

where $\Delta \varphi$ is the variation of the magnetic flux and $t$ is the time. This equation indicates that the self-induced electromotive force is characterized by the change rate of the enclosed magnetic flux which is determined by the relative motion between the bottom plate and the oscillator. Specifically, the value of $\dot{\Delta \varphi}$ is zero when the relative displacement reaches the two maximum values where the relative velocity between the bottom plate and the oscillator is zero at those times. Thus there are two zero voltage points in each period, which confirms that the self-sensing frequency equals the excitation frequency.

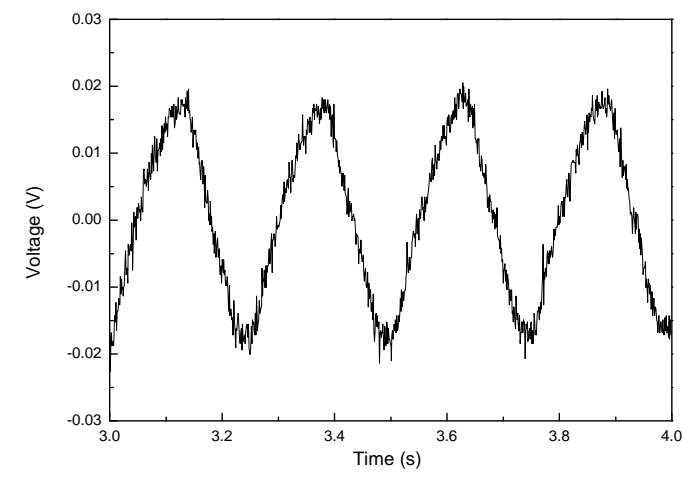

(a) $4 \mathrm{~Hz}$

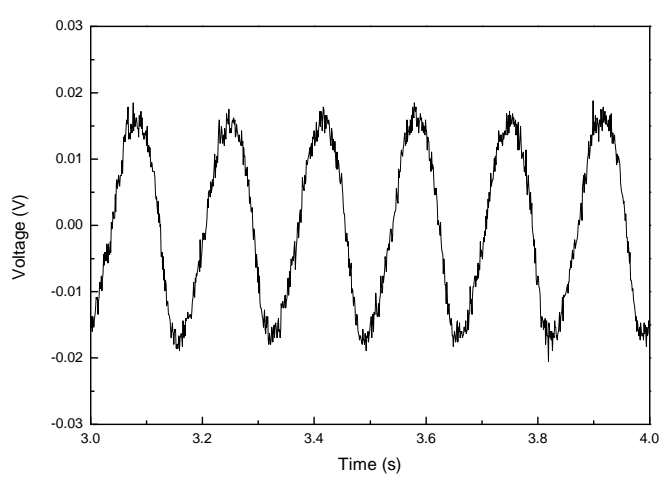

(a) $6 \mathrm{~Hz}$

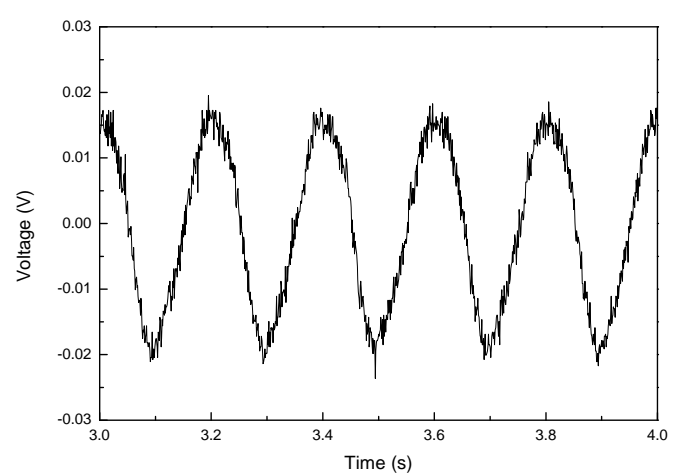

(b) $5 \mathrm{~Hz}$

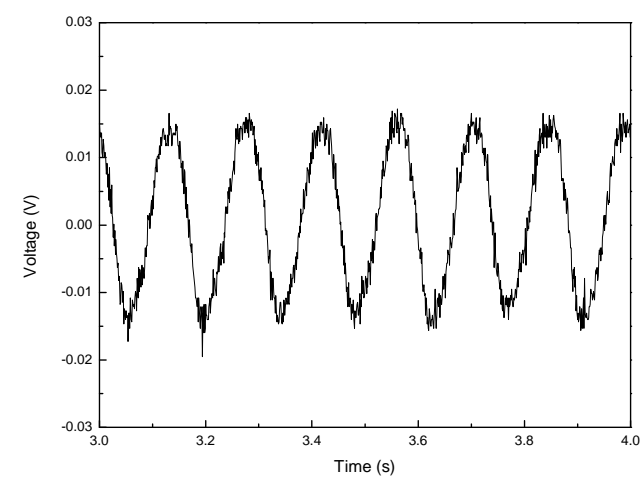

(b) $7 \mathrm{~Hz}$ 


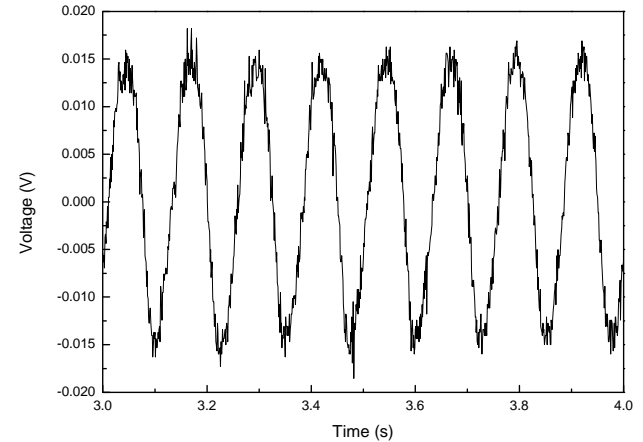

(a) $8 \mathrm{~Hz}$

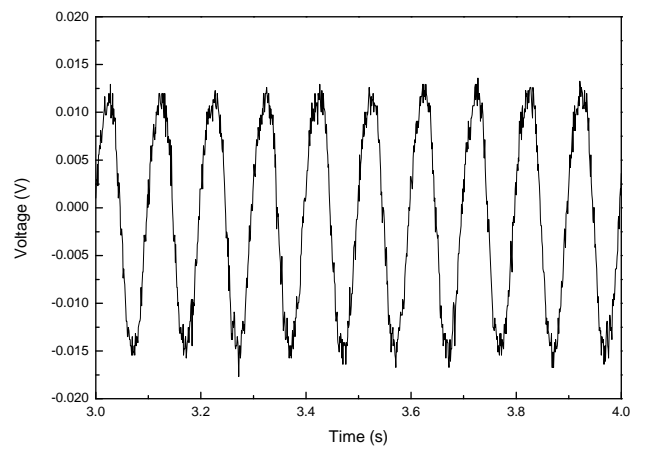

(a) $10 \mathrm{~Hz}$

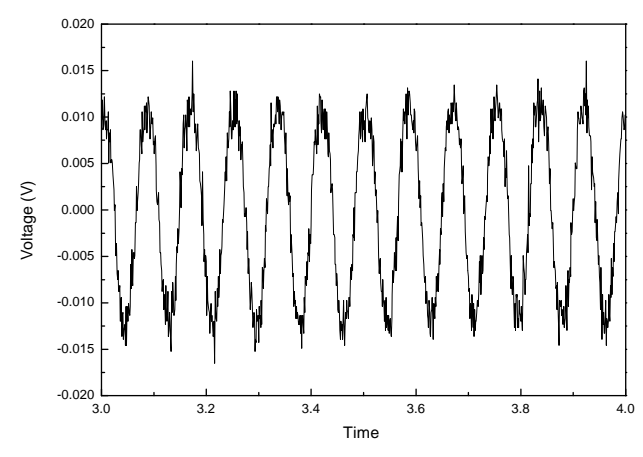

(a) $12 \mathrm{~Hz}$

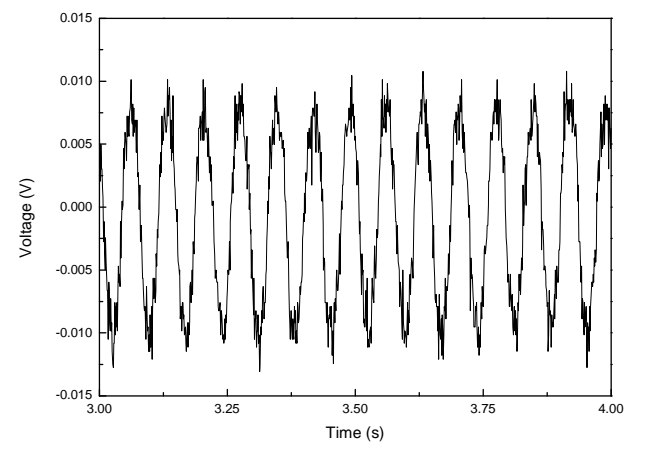

(a) $14 \mathrm{~Hz}$

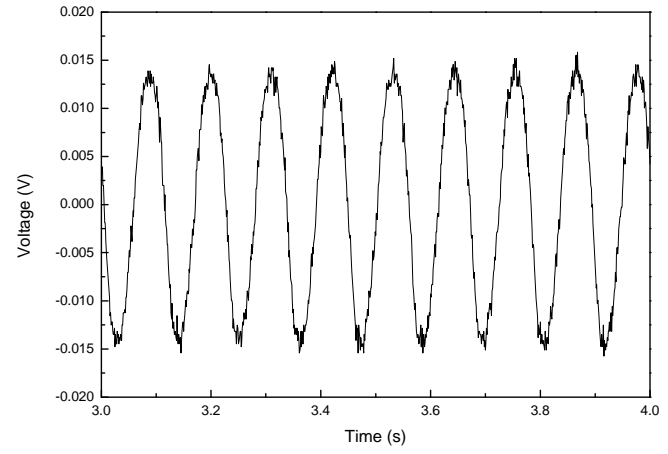

(b) $9 \mathrm{~Hz}$

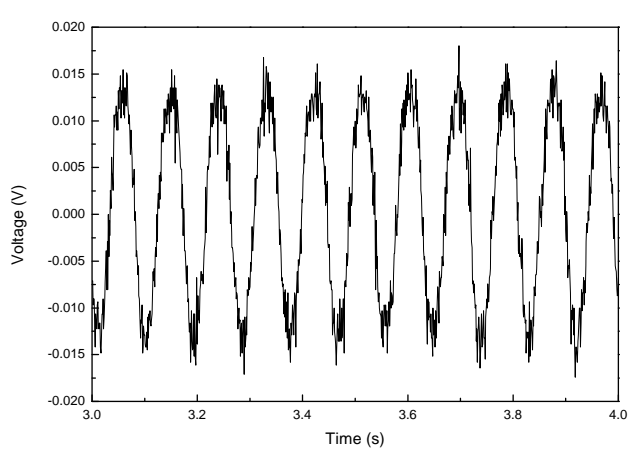

(b) $11 \mathrm{~Hz}$

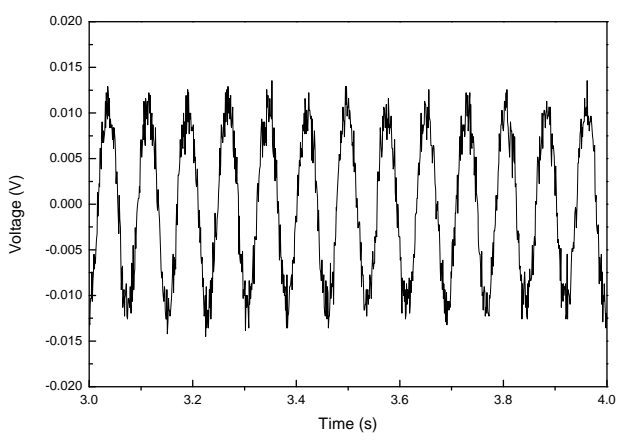

(b) $13 \mathrm{~Hz}$

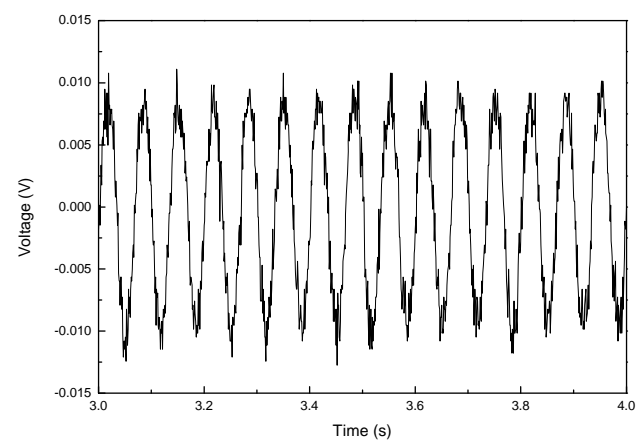

(b) $15 \mathrm{~Hz}$

Fig.6. The induced voltage of self-sensing coil in time domain 
In order to clearly demonstrate the frequency domain information of the self-sensing signal, the spectral power distribution of the self-sensing signals are analyzed and presented in Fig.7. From Fig.7, it can be seen that the energy of the self-sensing signals under each excitation vibration focuses on their corresponding frequencies, respectively. The linear relationship between the measured frequency and the excitation frequency is presented in Fig.8, which clearly shows that the measured frequency equals to the excitation frequency. The relationship between the measured frequency and the excitation frequency thus can be presented as:

$$
f_{m}=f_{e}
$$

where $f_{m}$ and $f_{e}$ are the measured dominant frequency and the excitation frequency, respectively.

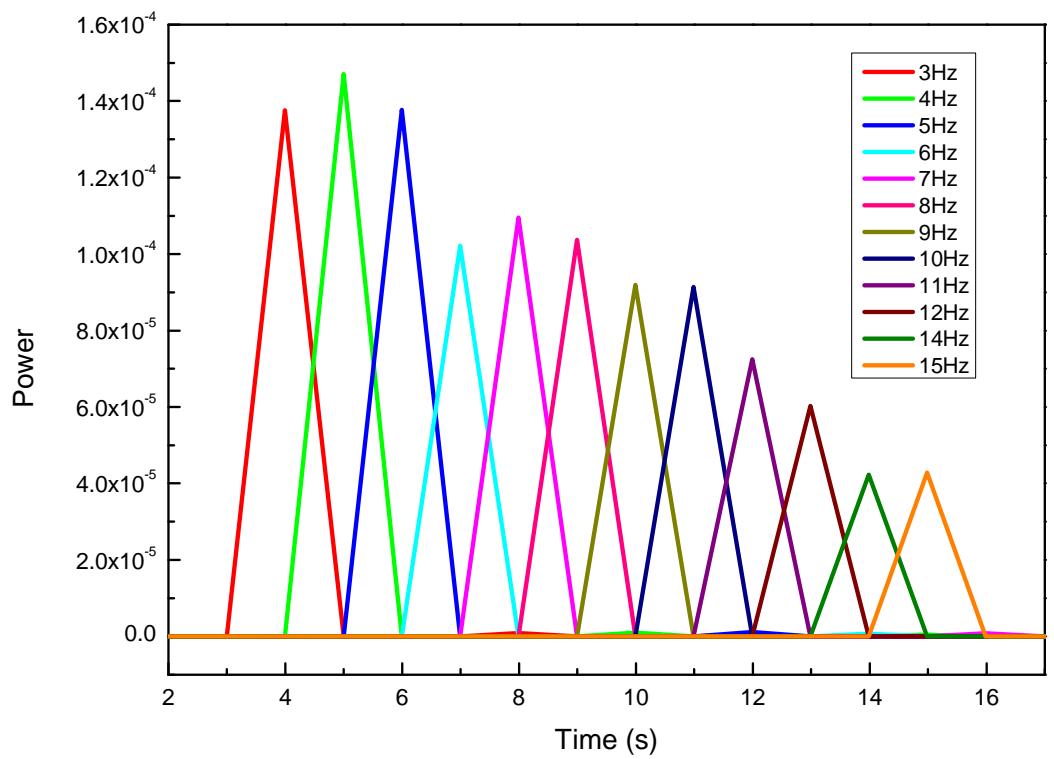

Fig.7 The power spectral density of the self-sensing signals 


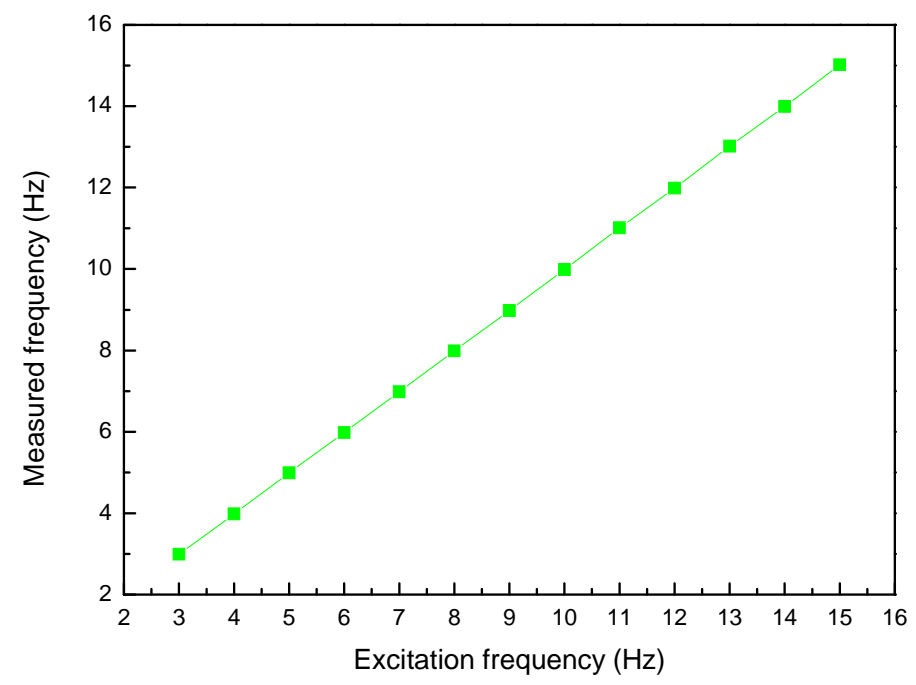

Fig.8 The relationship between excitation frequencies and measured frequencies The ability of the self-sensing coil to identify the excitation frequency of a single-frequency vibration has been verified. In order to further verify its ability to identify the dominant frequency from composite frequency vibration, the performances of the self-sensing coil with respect to three different composite frequency vibrations were investigated. The three different vibration sources are shown as equation (11) to equation (13), respectively. Each of the three vibrations is the sum of three items with different frequencies which are $4 \mathrm{~Hz}, 6 \mathrm{~Hz}$ and $8 \mathrm{~Hz}$, respectively, and different amplitudes. Take equation (11) as an example, the three amplitudes for the three items are 4, 2, and 1, respectively, therefore the power of this vibration should focus on the first item and the dominant frequency should be $4 \mathrm{~Hz}$. Similarly, the domain frequency for equation (12) and equation (13) is $6 \mathrm{~Hz}$ and $8 \mathrm{~Hz}$, respectively.

$$
\begin{aligned}
& y_{1}=4 \sin 8 \pi t+2 \sin 12 \pi t+1 \sin 16 \pi t \\
& y_{2}=1 \sin 8 \pi t+4 \sin 12 \pi t+2 \sin 16 \pi t \\
& y_{3}=1 \sin 8 \pi t+2 \sin 12 \pi t+4 \sin 16 \pi t
\end{aligned}
$$

Fig. 9 shows the self-sensed signals in time domain when the system was run by the above three excitations, respectively. It is clear that the waveforms are increasingly denser from Fig. 9(a) to Fig. 9 (c) due to the reason that the dominant frequency is increasingly bigger. Fig. (10) shows the frequency analysis of the self-sensed signals for the three excitations. For the first excitation (corresponding to equation (11)), the power mainly focused around $4 \mathrm{~Hz}$, then 
$6 \mathrm{~Hz}$, and at last $8 \mathrm{~Hz}$. This means that the dominant frequency is $4 \mathrm{~Hz}$, which matches the provided dominant frequency. Similarly, the dominant power concentrated at $6 \mathrm{~Hz}$ for equation (12) and $8 \mathrm{~Hz}$ for equation (13). These experimental results prove that this selfsensing absorber can exactly self-sense the dominant frequency not only for sing-frequency excitations but the composite frequency excitations as well.

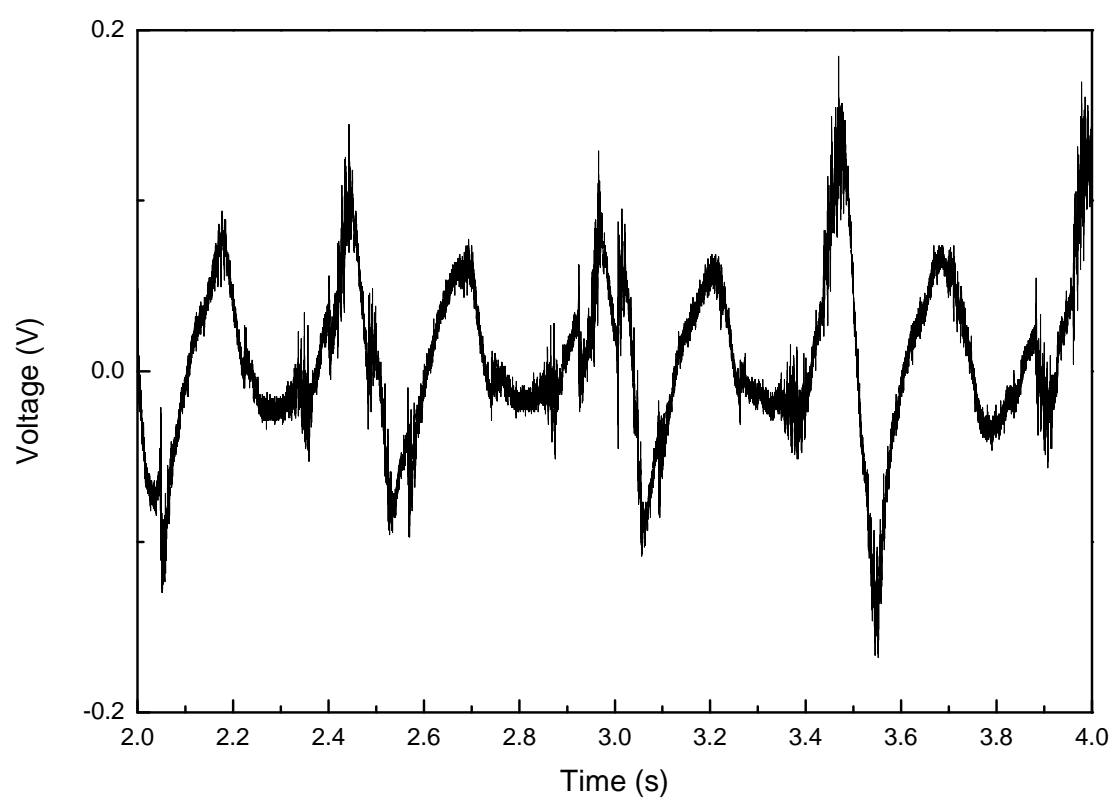

(a) $y_{1}$

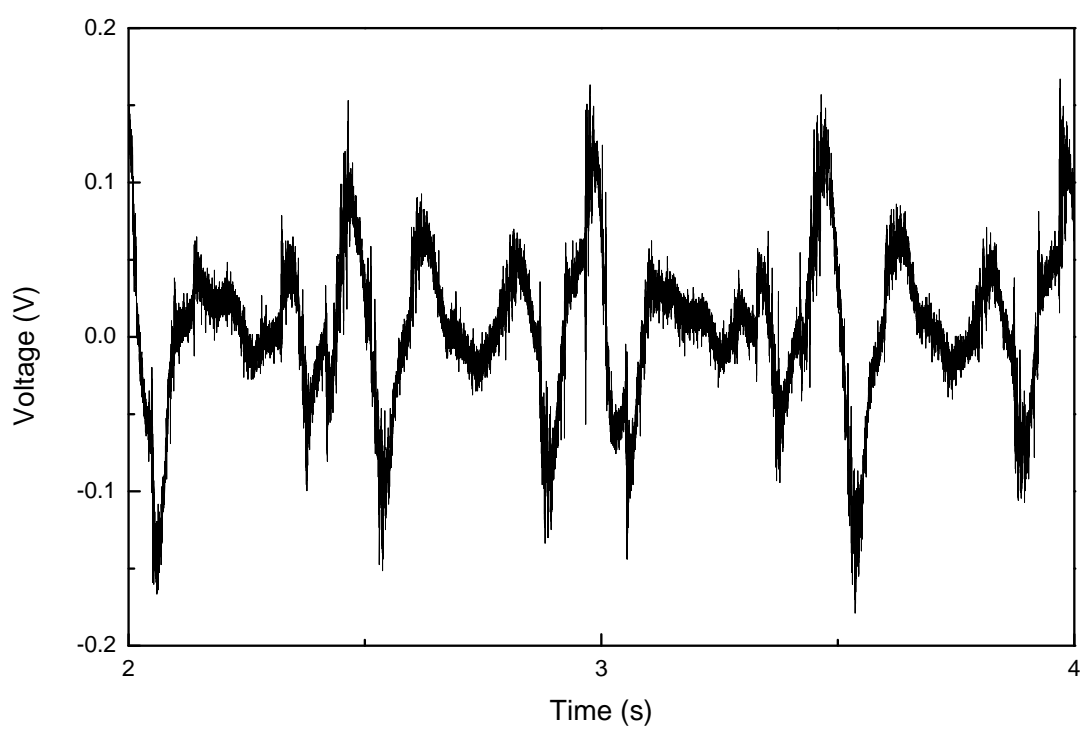

(b) $y_{2}$ 


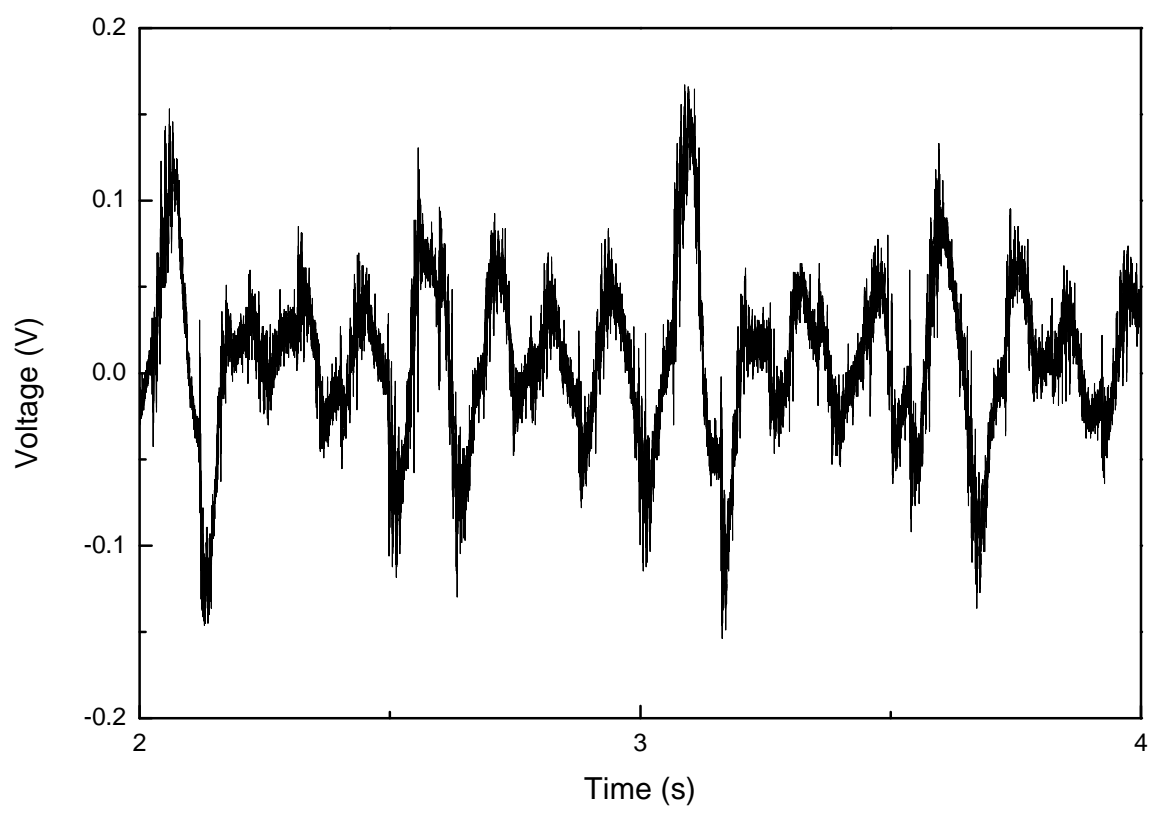

(c) $y_{3}$

Fig.9. The induced voltages of the self-sensing coil under composite excitation in time domain

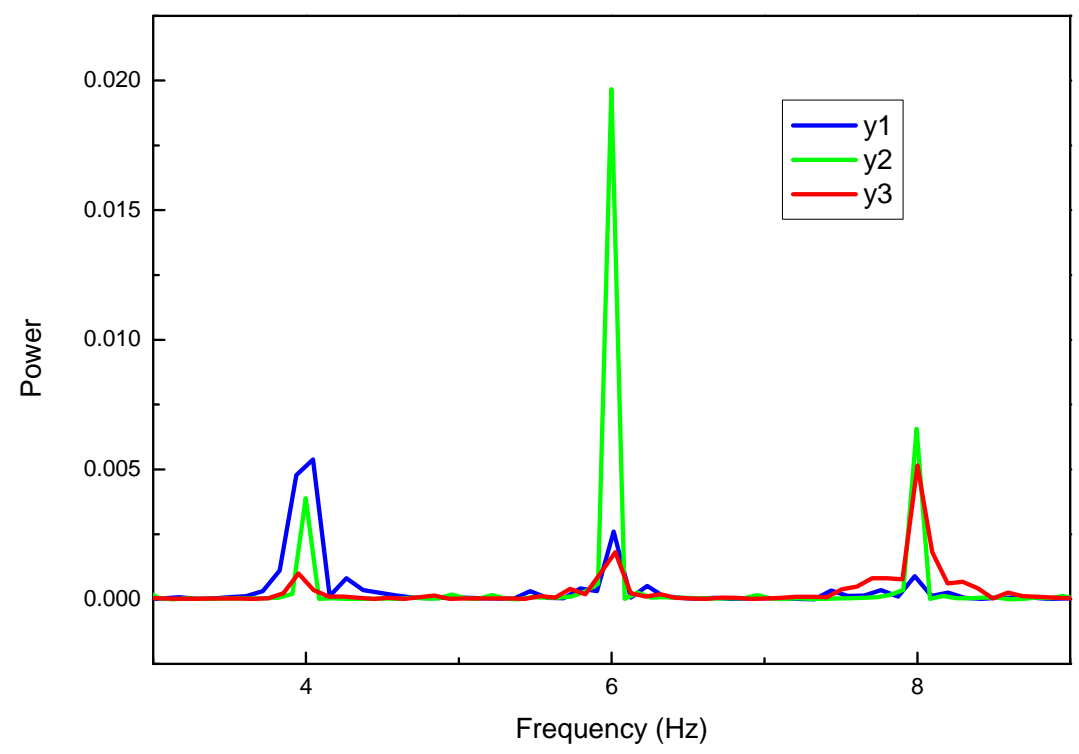

Fig.10. The induced voltages of the self-sensing coil under composite excitation in frequency domain. 

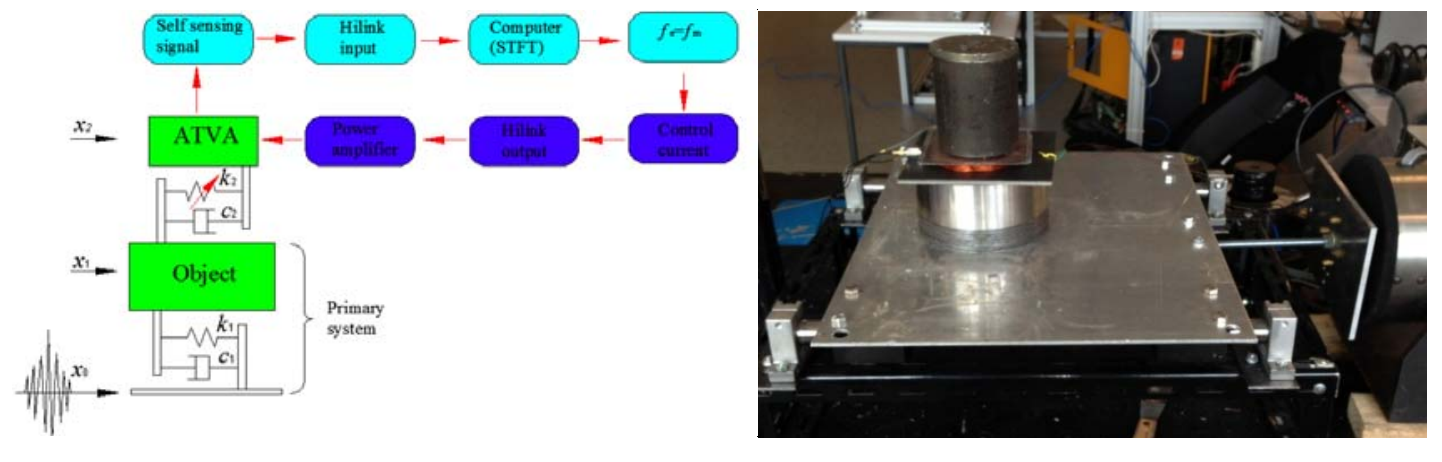

Fig.11. Vibration absorption evaluation system for self-sensing MRE absorber

This section verified the vibration attenuation effectiveness of the self-sensing absorber and compared it with the passive absorber. As Fig.11 shows, the MRE absorber was mounted onto the protected object whose natural frequency is $6.5 \mathrm{~Hz}$. The system dynamics are described by equations (14) and (15). The shaker supplied a sinusoidal excitation with a scan frequency from $3 \mathrm{~Hz}$ to $14 \mathrm{~Hz}$ to the evaluation system. In order to verify the effectiveness of the self-sensing absorber, the self-sensing signal from the self-sensing coil was passed to the computer via a HILINK (ZELTOM). The measured self-sensing voltage signals were firstly processed by the short time Fourier transform (STFT) method [28] to obtain its dominant frequency. According to the calculated excitation frequency, a current signal for excitation coil can be determined from the relationship between excitation currents and natural frequencies of MRE absorber in Fig.5. The current signal was amplified by a power amplifier and then applied to the MRE absorber so as to change the stiffness of the absorber and to trace the excitation frequency. The detailed control system can be seen in Fig.11. As a compare, the MRE absorber without current is defined as the passive absorber and its natural frequency is $6.5 \mathrm{~Hz}$. An accelerometer was mounted onto the protected object to measure its acceleration.

$$
\begin{aligned}
& \mathrm{m}_{2} \ddot{x}_{2}+\mathrm{k}_{2}\left(x_{2}-x_{1}\right)+\mathrm{c}_{2}\left(\dot{x}_{2}-\dot{x}_{1}\right)=0 \\
& \mathrm{~m}_{1} \ddot{x}_{1}+\mathrm{k}_{2}\left(x_{1}-x_{2}\right)+\mathrm{c}_{2}\left(\dot{x}_{1}-\dot{x}_{2}\right)+\mathrm{k}_{1}\left(x_{1}-x_{0}\right)+\mathrm{c}_{1}\left(\dot{x}_{1}-\dot{x}_{0}\right)=0
\end{aligned}
$$

where $m_{1}=6.5 \mathrm{~kg}$ and $m_{2}=3 \mathrm{~kg}$ are the masses of object and oscillator, respectively, $\ddot{x}_{1}$ and $\ddot{x}_{2}$ are the accelerations of the protected object and oscillator, $\mathrm{k}_{1}=10830 \mathrm{~N} / \mathrm{m}$ is the lateral stiffness of primary system and $\mathrm{k}_{2}$ is the lateral stiffness of the MRE absorber, $\mathrm{c}_{1}=210 \mathrm{~N} /(\mathrm{m} / \mathrm{s})$ and $\mathrm{c}_{2}$ are the lateral damping of the primary system and MRE absorber. For the passive absorber, $\mathrm{k}_{2}$ and $\mathrm{c}_{2}$ are constant values while the $\mathrm{k}_{2}$ and $\mathrm{c}_{2}$ vary according different excitation frequencies for the self-sensing MRE absorber. 


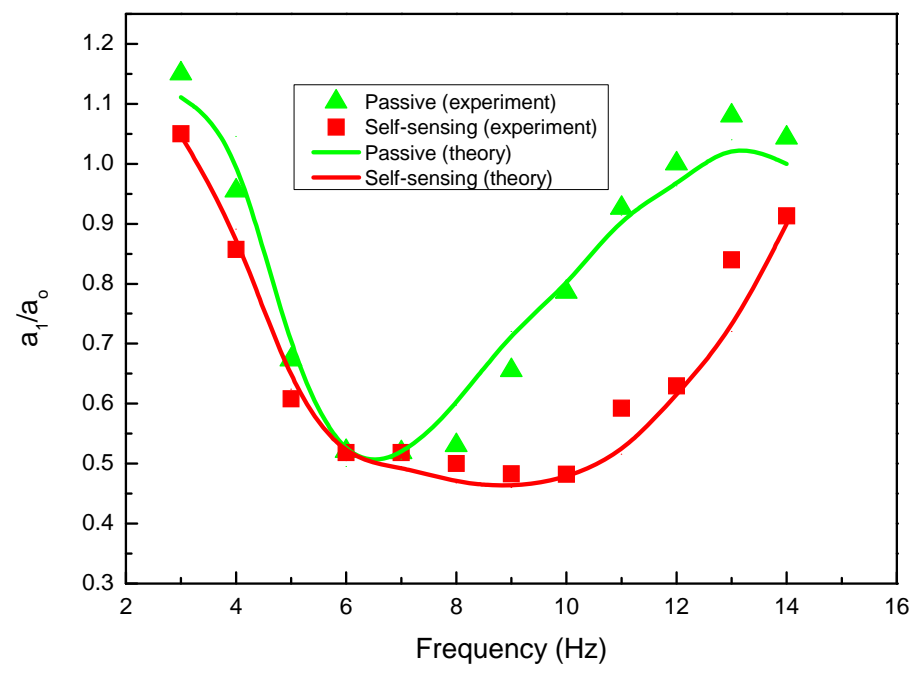

Fig.12. A comparison between the passive and self-sensing MRE absorber

Fig. 12 shows the comparison of the vibration absorption ability between the passive and the self-sensing absorber theoretically and experimentally. The absorption efficiency, $\gamma$, shown by the $\mathrm{Y}$ axis, is calculated by:

$$
\gamma=a_{1} / a_{0}
$$

where $a_{1}$ is the acceleration of the protected object with absorber, and $a_{\mathrm{O}}$ is the acceleration of the protected object without absorber. The less the $\gamma$ is, the more effective the absorber is. The first conclusion from this figure is that the experimentally obtained data matches well with the simulated results for both the passive and self-sensing absorber. For the passive absorber where the lines are shown in green, its best performance occurred when the external excitation frequency equals to its natural frequency $(6.5 \mathrm{~Hz})$ but its effective range is limited to a very small region as $\gamma$ increases when the excitation frequency deviates from $6.5 \mathrm{~Hz}$. The testing results shown in red presents that the self-sensing absorber is more effective on reducing vibrations than the passive absorber is, which verified the effectiveness of the selfsensing absorber on vibration reduction.

The above section verified the good vibration reduction performance of the self-sensing MRE absorber on single frequency vibration. The vibration reduction performance of the selfsensing MRE absorber with respect to a composite frequency vibration was investigated so as to further verify its vibration absorption capability. The vibration source is a function of time, shown as equation (17), which is the sum of two items with different frequencies which are 
$5 \mathrm{~Hz}, 9 \mathrm{~Hz}$, respectively, and different amplitudes. Additionally, it can be seen that the vibration expression is a piecewise function with the time threshold being $15 \mathrm{~s}$. Before the running time reaches $15 \mathrm{~s}$, the two amplitudes for the two items are 1 and 4 , respectively, therefore the power of equation should focus on the second item and the dominant frequency should be $9 \mathrm{~Hz}$. Similarly, the dominant frequency of the vibration signal after $15 \mathrm{~s}$ is $5 \mathrm{~Hz}$. The testing system is the same as shown by Fig. (11). The STFT algorithm is used to analyze the self-sensed signal and identify the dominant vibration frequency. In order to show that the self-sensing absorber can identify the dominant frequency, the MRE absorber under two constant currents were defined as passive 1 and passive 2, whose natural frequencies are $5 \mathrm{~Hz}$ and $9 \mathrm{~Hz}$, respectively. The testing results are shown in Fig. (13) and Fig. (14)

$$
y_{4}=\left\{\begin{array}{cc}
1 \sin 10 \pi t+4 \sin 18 \pi t \quad(0 \leq t<15) \\
4 \sin 10 \pi t+1 \sin 18 \pi t \quad(15 \leq t<30)
\end{array}\right.
$$

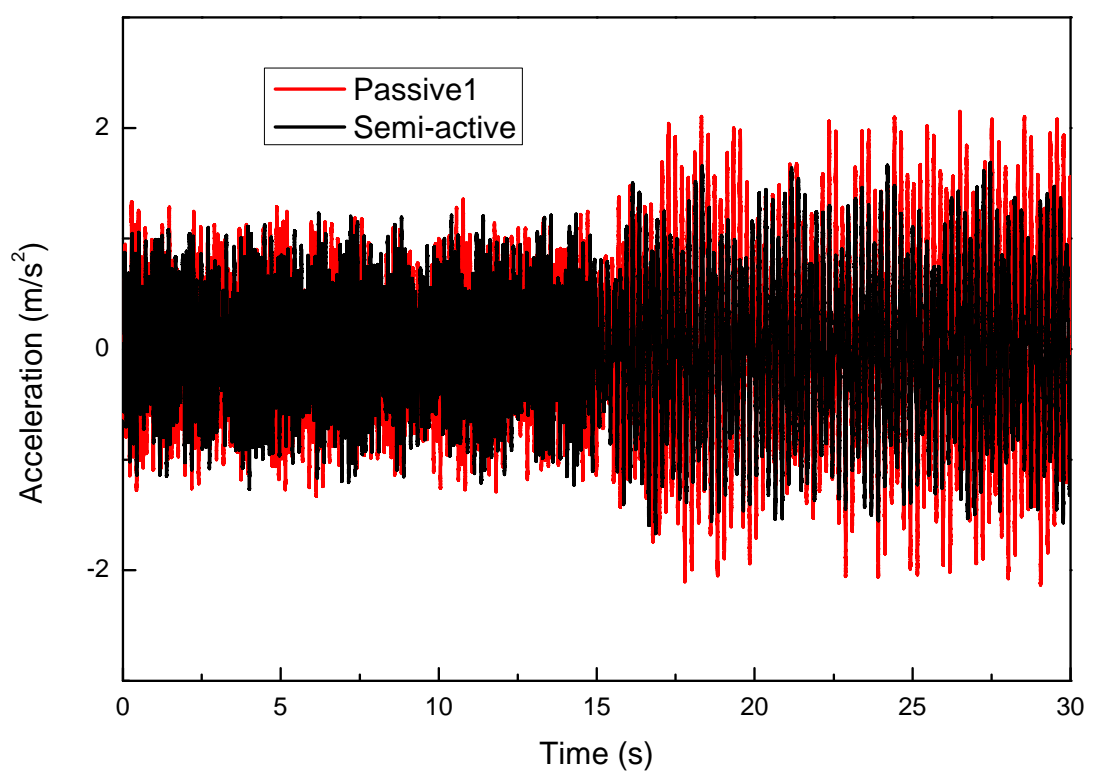

Fig.13. Comparison between passive absorber1 with semi-active absorber 


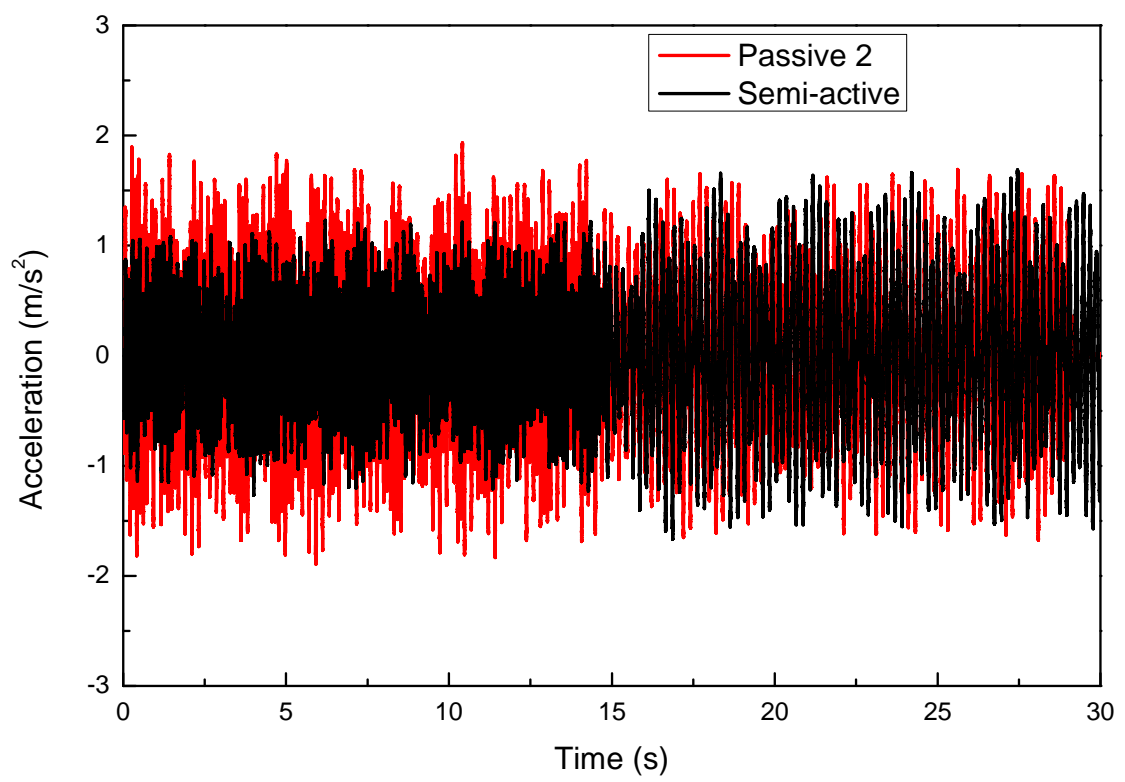

Fig.14. Comparison between passive absorber2 with semi-active absorber

Fig. 13 compares the testing results of the semi-active self-sensing absorber with the passive absorber 1 whose natural frequency is $9 \mathrm{~Hz}$. From this figure, it can be seen that the performances of the two absorbers are similar when the running time is before $15 \mathrm{~s}$. This is because the natural frequency of the passive absorber1 matches the dominant excitation frequency. When the running time passes $15 \mathrm{~s}$, however, the performance of the passive absorber 1 is much worse than semi-active absorber. The reason is the dominant frequency of the excitation changes from $9 \mathrm{~Hz}$ to $5 \mathrm{~Hz}$ when the running time passes through $15 \mathrm{~s}$. The selfsensing MRE absorber can track this change and vary its natural frequency to $5 \mathrm{~Hz}$ while the passive absorber1 cannot. Similar observations can be found in Fig. 14 that the semi-active self-sensing absorber can track the dominant frequency of the excitation during the whole time history while the passive absorber 2 can only do this when the dominant frequency of excitation equals to its natural frequency. In summary, the testing results from Fig. 13 and Fig. 14 verified the self-sensing absorber can identify the dominant frequency from composite frequency vibration and performs well regarding the composite frequency vibration control.

\section{Conclusion}

A self-sensing MRE absorber was designed, analysed, and tested in this paper. The frequency-shift experimental results showed that the proposed absorber can increase or decrease its natural frequency, i.e., the natural frequency ranges from $4.8 \mathrm{~Hz}$ at $-3 \mathrm{~A}$ to $11.3 \mathrm{~Hz}$ 
at $3 \mathrm{~A}$ with a change as high as $235 \%$. The experiment for verifying self-sensing capability clearly shows that the measured frequency of the self-induced voltage equals to the excitation frequency. To evaluate how effectively the self-sensing MRE absorber could control vibration, the vibration absorption evaluation experiment was conducted to compare the effectiveness of the passive and self-sensing MRE absorber. The compare result shows that the self-sensing MRE absorber is more effective than the passive system, which verified the effectiveness of the self-sensing and vibration absorption capabilities of the self-sensing MRE absorber.

\section{Acknowledgements}

This research is supported by ARC Discovery Grants (Nos. 150102636, 140100303), the National Natural Science Foundation of China (Nos. 51205100, \& 51328502), 111 project (No. B12019) and the University of Wollongong and China Scholarship Council joint scholarships.

\section{References:}

[1] K. Liu,and J. Liu, "The damped dynamic vibration absorbers: revisited and new result," Journal of sound and vibration, vol. 284, pp. 1181-1189, 2005.

[2] C. L. Davis, and G.A. Lesieutre, "An actively tuned solid-state vibration absorber using capacitive shunting of piezoelectric stiffness," Journal of sound and vibration, vol. 232, pp. 601-617, 2000.

[3] K. Nagaya, A. Kurusu, S. Ikai, Y. Shitani, "Vibration control of a structure by using a tunable absorber and an optimal vibration absorber under auto-tuning control," Journal of sound and vibration, vol. 228, pp. 773$792,1999$.

[4] P. Walsh and J. Lamancusa, "A variable stiffness vibration absorber for minimization of transient vibrations," Journal of sound and vibration, vol. 158, pp. 195-211, 1992.

[5] J. Yang, H. Du, W. Li, Y. Li, J. Li, S. Sun, and H. Deng, "Experimental study and modeling of a novel magnetorheological elastomer isolator," Smart Materials and Structures, vol. 22, art. no. 117001, 2013.

[6] S. Sun, Y. Chen, J. Yang, T. F. Tian, H. X. Deng, W. H. Li, H. Du, G. Alici, "The development of an adaptive tuned magnetorheological elastomer absorber working in squeeze mode," Smart Materials and Structures, vol. 23, art. no. 075009, 2014.

[7] J. Yang, S. S. Sun, H. Du, W. H. Li, G. Alici, H. X. Deng," A novel magnetorheological elastomer isolator with negative changing stiffness for vibration reduction," Smart Materials and Structures, vol. 23, art. no. $105023,2014$.

[8] Y. Li, J. Li, W. H. Li, H. Du, "A state-of-the-art review on magnetorheological elastomer devices," Smart Materials and Structures, vol. 23, art. no. 123001, 2014. 
[9] K. M. Popp, M. Kröger, W. H. Li, X. Z. Zhang, P. B. Kosasih, "MRE properties under shear and squeeze modes and applications," Journal of Intelligent Material Systems and Structures, vol. 21, pp. 1471-1477, 2010 .

[10] J. M. Ginder, W.F. Schlotter, and M.E. Nichols, "Magnetorheological elastomers in tunable vibration absorbers," in SPIE's 8th Annual International Symposium on Smart Structures and Materials, vol. 4331, pp. 103-110, July 2001.

[11] H. Deng, G. X, and L. Wang, "Development of an adaptive tuned vibration absorber with magnetorheological elastomer," Smart materials and structures, vol. 15, p. N111, 2006.

[12] H. X. Deng and X. Gong, "Application of magnetorheological elastomer to vibration absorber," Communications in Nonlinear Science and Numerical Simulation, vol. 13, pp. 1938-1947, 2008.

[13] N. Hoang, N. Zhang, and H. Du, "A dynamic absorber with a soft magnetorheological elastomer for powertrain vibration suppression," Smart Materials and Structures, vol. 18, art. no. 074009, 2009.

[14] 18. X. Zhang and W. Li, "Adaptive tuned dynamic vibration absorbers working with MR elastomers," Smart Structures and Systems, vol. 5, pp. 517-529, 2009.

[15] S. Sun, X. Deng, J. Yang, W. Li, H. Du, G. Alici, "Performance evaluation and comparison of magnetorheological elastomer absorbers working in shear and squeeze modes," Journal of Intelligent Material Systems and Structures, publish online, doi: 1045389X14568819, 2015.

[16] C. Peng and X. L. Gong, "Active-adaptive vibration absorbers and its vibration attenuation performance," Applied Mechanics and Materials, vol. 312, pp. 262-267, 2013.

[17] G. Liao, X. L. Gong, C. J. Kang, S. H. Xuan, "The design of an active-adaptive tuned vibration absorber based on magnetorheological elastomer and its vibration attenuation performance," Smart materials and structures, vol. 20, art. no. 075015, 2011.

[18] Y. T. Choi and N. M. Wereley, "Self-powered magnetorheological dampers," Journal of vibration and acoustics, vol. 131, art. no. 044501, 2009.

[19] B. Sapiński, "Experimental study of a self-powered and sensing MR-damper-based vibration control system," Smart Materials and Structures, vol. 20, art. no. 105007, 2011.

[20] D. Q. Truong and K. K. Ahn, "Identification and application of black-box model for a self-sensing damping system using a magneto-rheological fluid damper," Sensors and Actuators A: Physical, vol. 161, pp. 305$321,2010$.

[21] D. Wang and T. Wang, "Principle, design and modeling of an integrated relative displacement self-sensing magnetorheological damper based on electromagnetic induction," Smart Materials and Structures, vol. 18, art. no. 095025, 2009.

[22] D. Wang, X. X. Bai, W. H. Liao, "An integrated relative displacement self-sensing magnetorheological damper: prototyping and testing," Smart Materials and Structures, vol. 19, art. no. 105008, 2010.

[23] G. Hu, W. Zhou, M. Liao and W. H. Li, "Static and dynamic experiment evaluations of a displacement differential self-induced magnetorheological damper," Shock and Vibrations, vol. 2015, art. no. 295294, 2015 .

[24] C. Chen and W. H. Liao, "A self-sensing magnetorheological damper with power generation," Smart Materials and Structures, vol. 21, p. 025014, 2012.

[25] K. Lam, Z. H. Chen, Y. Q. Ni, H. Chan, "A magnetorheological damper capable of force and displacement sensing," Sensors and Actuators A: Physical, vol. 158, pp. 51-59, 2010.

[26] G. Hu, Y. Rui and W. H. Li, "Design and development of a novel displacement differential self-induced magnetorheological damper," Journal of Intelligent Material Systems and Structures, vol. 26, pp. 527-540, 2015.

[27]. S. Sun, X. Deng, J. Yang, W. Li, H. Du, G. Alici, M. Nakano, "An adaptive tuned vibration absorber based on multilayered MR elastomers," Smart Materials and Structures, vol. 24, art. no. 045045, 2015.

[28] S. Nagarajaiah and N. Varadarajan, "Short time Fourier transform algorithm for wind response control of buildings with variable stiffness TMD," Engineering Structures, vol. 27, pp. 431-441, 2005. 